\title{
Cholinergic receptor nicotinic alpha 5 subunit polymorphisms are associated with smoking cessation success in women
}

Paulo Roberto Xavier Tomaz', Juliana Rocha Santos', Jaqueline Scholz², Tânia Ogawa Abe², Patrícia Viviane Gaya², André Brooking Negrão ${ }^{1}$, José Eduardo Krieger ${ }^{1}$, Alexandre Costa Pereira ${ }^{1}$ and Paulo Caleb Júnior Lima Santos ${ }^{1,3^{*}}$

\begin{abstract}
Background: The identification of variants in the nicotinic acetylcholine receptor (nAChR) subunit genes associated with smoking phenotypes are increasingly important for prevention and treatment of nicotine dependence. In the context of personalized medicine, the aims of this study were to evaluate whether cholinergic receptor nicotinic alpha 2 (CHRNA2), cholinergic receptor nicotinic alpha 3 (CHRNA3), cholinergic receptor nicotinic alpha 5 (CHRNA5) and cholinergic receptor nicotinic beta 3 (CHRNB3) polymorphisms were associated with nicotine dependence severity, and to investigate possible pharmacogenetics markers of smoking cessation treatment.
\end{abstract}

Methods: This study cohort enrolled 1049 smoking patients who received pharmacological treatment (varenicline, varenicline plus bupropion, bupropion plus/or nicotine replacement therapy). Smoking cessation success was considered for patients who completed 6 months of continuous abstinence. Fagerström test for nicotine dependence (FTND) and Issa situational smoking scores (Issa score) were analyzed for nicotine dependence. CHRNA2 (rs2472553), CHRNA3 (rs1051730), CHRNA5 (rs16969968 and rs2036527) and CHRNB3 (rs6474413) polymorphisms were genotyped by high resolution melting analysis.

Results: Females with GA and AA genotypes for CHRNA5 rs 16969968 and rs2036527 polymorphisms had higher success rate in smoking cessation treatment: 44.0\% and 56.3\% (rs16969968), 41.5\% and 56.5\% (rs2036527), respectively, compared with carriers of the GG genotypes: $35.7 \%$ (rs 16969968), 34.8\% (rs2036527), ( $P=0.03, n=389$; $P=0.01, n=391)$. The GA or AA genotypes for the rs 16969968 and rs 2036527 were associated with higher odds ratio for success in women $(\mathrm{OR}=1.63 ; 95 \% \mathrm{Cl}=1.04$ to $2.54 ; P=0.03$ and $\mathrm{OR}=1.59,95 \% \mathrm{Cl}=1.02$ to $2.48 ; P=0.04$; respectively). We did not find association of these polymorphisms with nicotine dependence related scores. Polymorphisms in the CHRNA2, CHRNA3 and CHRNB3 genes were not associated with the phenotypes studied.

Conclusion: CHRNA5 rs16969968 and rs2036527 were associated with higher success rate in the smoking cessation treatment in women. These findings might contribute to advances in personalized medicine.

Keywords: CHRNA5, Nicotine dependence, Smoking cessation, Polymorphism

\footnotetext{
* Correspondence: paulo.caleb@unifesp.br

${ }^{1}$ Laboratory of Genetics and Molecular Cardiology, Instituto do Coracao

(InCor), Hospital das Clinicas HCFMUSP, Faculdade de Medicina, Universidade

de Sao Paulo, Sao Paulo, SP, Brazil

${ }^{3}$ Department of Pharmacology, Universidade Federal de Sao Paulo -

UNIFESP, Sao Paulo, SP, Brazil

Full list of author information is available at the end of the article
} 


\section{Background}

Smoking is a serious public health problem, contributing significantly to the risk of death from cancers, cardiovascular diseases, lung disorders and stroke. Public health agencies aim to reduce tobacco use; however, relapse is common during smoking treatment programs. According to the World Health Organization, if current trends continue, the annual number of deaths from diseases related to smoking could double from five million in 2000 to 10 million in 2020 [1, 2].

Studies have shown that although smoke toxicity is related to many components of the cigarette, nicotine is responsible for the development of dependence [3, 4]. Smokers in Brazil who want to quit have the following first-line pharmacological treatments: nicotine replacement therapy (NRT), bupropion (an inhibitor of the reuptake of norepinephrine, dopamine and nicotinic antagonist) and, varenicline (a partial agonist of nicotinic acetylcholine receptor - $\mathrm{nAChR}-\alpha 4 \beta 2$ ) [5-7].

Cigarette smoking is classified as a complex behavior comprising multiple stages such as initiation, experimentation, regular use, addiction, cessation and relapse [8, 9]. To better understand the role played by genes in those stages, twin studies, and allelic association studies of candidate genes and large genome wide-association studies are increasingly required [8-10].

In the last ten years, several studies have identified loci, mainly in chromosome 8 and 15, which are highly involved in the pathogenesis of nicotine dependence (ND) process. These regions of the genome include genes encoding various subunits of the nAChR. These receptors are expressed in the brain and are thought to be responsible for mediating the addictive effects of nicotine $[1,8,10-14]$. Therefore, studies have shown the association of polymorphisms in genes encoding the subunits of nicotinic receptors (CHRNA2, CHRNA3, CHRNA5, CHRNB3) with the number of cigarettes per day, ND and risk for developing lung cancer $[1,8,13$, $15,16]$.

In the context of personalized medicine, the aims of the present study were to evaluate whether CHRNA2, CHRNA3, CHRNA5 and, CHRNB3 polymorphisms were associated with level of dependency and, response to smoking cessation therapies in patients from a smoking cessation assistance program.

\section{Methods}

\section{Study population}

The study sample included 1049 smoking patients from PAF (Programa de Assistência ao Fumante/Smoker Assistance Program), Heart Institute (InCor), University of Sao Paulo Medical School, Sao Paulo, Brazil, between January, 2007 and November, 2014. The study protocol was approved by the Institutional Ethics Committee
(Comissão de Ética para Análises de Projetos de Pesquisa - CAPPesq - 4024/14/004), and written informed consent was obtained from all participants prior to entering the study. Data from patients who had outcome in smoking treatment were obtained from the PAF database.

The PAF protocol consists of an initial medical visit plus an average of 4 follow-up medical visits for 12 weeks. The follow-up was made by phone in patients who did not continue to come on scheduled medical visits. Clinical data and end-expiratory exhaled carbon monoxide $(\mathrm{CO})$ were collected in all visits. Data about demographic, socio-economic, clinical data and previously diagnosed diseases were acquired at the consult. During clinical anamnesis patients were questioned whether they were undergoing treatment or had a diagnosis of depression and/or anxiety. Patients received behavioral counseling and drug treatment from physicians specialized in smoking cessation. Bupropion plus/or NRT was prescribed for patients who smoked less than 1 cigarette pack per day. Varenicline was prescribed for patients who smoked 1 or more cigarette pack(s) per day, or who failed in previous attempts with bupropion plus/or NRT. The decision to start co-administration of bupropion and varenicline was made if the patient was unable to quit smoking after 2 or 3 months of starting varenicline use, or if the patient stopped smoking, but presented moderate or intense discomfort abstinence symptoms. Continuous abstinence (CA) was investigated after 6 months of starting pharmacotherapy. Smoking status (outcome) was divided into: success group (patients who completed 6 months of CA confirmed by end-expiratory exhaled carbon monoxide $<4 \mathrm{ppm})$, relapse group (patients who did not complete 6 months of $\mathrm{CA}$ ), and resistant group (patients who never achieved CA after starting drug treatment) $[17,18]$.

\section{FTND and Issa scores}

The Fagerström Test for Nicotine Dependence (FTND) and the Issa Situational Smoking Score (Issa score) were used to assess smoking behavior. The FTND is comprised of six questions with different weights for each question, generating a score ranging from 0 to 10 points and individuals are grouped into five categories: 1-2 points = very low dependence; $3-4$ points = low dependence; 5 points $=$ medium dependence; $6-7$ points $=$ high dependence; and 8-10 points = very high dependence [19]. The Issa score is comprised of four questions, one point for each affirmative answer, generating a scores ranging from 0 to 4 points. Individuals are grouped into categories: 1 point = low dependence; $2-3$ points $=$ medium dependence; 4 points $=$ high dependence [20].

The FTND is a revised version of the Fagerström Tolerance Questionnaire (FTQ) and it is based in the 
cigarette consumption, while the Issa score is based on the psychoactive effects of nicotine on cognitive processes, attention, concentration, mood, well-being and pleasure [20]. The Issa score is used at the PAF to reclassify nicotine dependent patients who achieved a FTND score below 5 but have otherwise considerable ND level in relation to the psychoactive effects of nicotine. As consequences of the psychoactive action of nicotine, smokers can have behaviors that may indicate the intensity of addiction [20].

\section{Genotyping}

The criteria for selection of these polymorphisms was the number of significant replications in genetic association studies.

Genomic deoxyribonucleic acid (DNA) from subjects was extracted from peripheral blood following a standard salting-out procedure. Genotyping for the CHRNA2 rs2472553 (c.674C > T), CHRNA3 rs1051730 (c.645C > T), CHRNA5 rs16969968 (c.1192G >A), CHRNA5 rs2036527 (g.78559273G > A) and CHRNB3 rs6474413 (g.42695921G > A) were performed by polymerase chain reaction (PCR) followed by high resolution melting (HRM) analysis according with previous studies [21, 22]. Amplification of the fragment for the CHRNA2 rs2472553, CHRNA3 rs1051730, CHRNA5 rs16969968, CHRNA5 rs2036527 and CHRNB3 rs6474413 were performed using the primers shown in Additional file 1: Table S1. As an example, Additional fil 2: Figure S1 shows normalized fluorescence by temperature graphs for the CHRNA5 rs16969968 polymorphism. Nine percent of the samples were randomly selected and reanalyzed as quality controls and gave identical results.

\section{Statistical analysis}

Continuous variables are presented as mean and standard deviation and categorical variables as frequencies. Chi-square test was performed for the comparative analysis of treatment outcome in the overall group of patients and groups of women and men according to the polymorphisms in CHRNA2, CHRNA3, CHRNA5 and CHRNB3 genes. The analysis of the Hardy-Weinberg equilibrium (HWE) was also performed using the chisquare test. The Student's t-test was used to compare values of the FTND score according to polymorphisms and also, to compare general and clinical characteristics between men and women. Linear regression models were conducted to evaluate the influence of polymorphisms in FTND in the presence of covariates: age, gender (male), race/self-declared color (white) and educational status. Logistic regression multivariate models were used to evaluate the odds ratio (OR) for success (versus relapse plus resistant) according to the polymorphisms. Covariates used in the models were: age, race/self-declared color (white), FTND score and drug group. Studies have tested additive effects, including some of the largest genetic studies on smoking behavior [23] and cessation [24]. However, the dominant model was chosen based on previous studies: CHRNA2 rs2472553 (CC vs CT + TT) [13], CHRNA3 rs1051730 (CC vs CT + TT) [25], CHRNA5 rs16969968 (GG vs GA + AA) [26], CHRNA5 rs2036527 (GG vs GA + AA) [27] and CHRNB3 rs6474413 (GG vs GA + AA) [28]. Statistical analyses were carried out using the SPSS software (v.16.0), with the level of significance set at $p \leq 0.05$.

\section{Results}

General, clinical, and genetic characteristics of patients

The clinical and demographic characteristics of the 1049 participants are shown in Table 1. Patients in the analysis had a mean age of $54.0 \pm 15.0$ years and $54.7 \%$ were female. Race/color self-declared white was $65.8 \%$. The non-white was composed by patients self-declared as blacks (7.2\%) and intermediates (23.9\%). In addition, Asians (3.0\%) and Amerindians (0.1\%) were enrolled. The minor allele frequencies and genotypic distributions for the rs2472553, rs1051730, rs16969968, rs2036527 and rs6474413 were in accordance with Hardy-Weinberg equilibrium (Additional file 1 Table S2).

\section{Success rate in smoking cessation according to genotypes}

Table 2 shows the success rate in smoking cessation for patients according to the genotypes for CHRNA2 rs2472553, CHRNA3 rs1051730, CHRNA5 rs16969968 and rs2036527 and CHRNB3 rs6474413 polymorphisms. The GA and AA genotypes for the CHRNA5 rs2036527 and rs16969968 polymorphisms were associated with higher rates of success in smoking cessation treatment in the female group $(n=389, n=391) ;(P=0.03, P=0.01)$, respectively. The frequencies of success according to genotypes among the drug treatment groups were not different. We found no association of CHRNA2 rs2472553, CHRNA3 rs1051730 and CHRNB3 rs6474413 polymorphisms with treatment outcome. The CHRNA2 rs2472553, CHRNA3 rs1051730 and CHRNB3 rs6474413 polymorphisms showed the following OR for success: 1.17 (95\% CI $=0.81-1.69, p=0.42) ; 1.02$ (95\% CI = 0.75-1.40, $p=0.88) ; \quad$ and $1.00 \quad(95 \% \quad \mathrm{CI}=0.57-1.75, \quad p=1.00)$, respectively.

Table 3 shows a multivariate logistic regression analysis for the success in smoking cessation according to the polymorphisms in CHRNA5 gene in women. The GA or AA genotypes for CHRNA5 rs16969968 and rs2036527 were associated with higher OR for success in women $(\mathrm{OR}=1.63 ; 95 \% \mathrm{CI}=1.04$ to $2.54 ; P=0.03)(\mathrm{OR}$ $=1.59 ; 95 \% \mathrm{CI}=1.02$ to $2.48 ; P=0.04)$, respectively. 
Table 1 Clinical and demographic characteristics of patients undergoing smoking cessation $(n=1049)$

\begin{tabular}{llll}
\hline & Women $(n=574)$ & Men $(n=475)$ & $P$ value \\
\hline Age (years) & $54 \pm 18$ & $54 \pm 11$ & 0.52 \\
Race/color self-declared, White (\%) & 62.2 & 69.3 & $27 \pm 5$ \\
Body mass index (Kg/m $\left.{ }^{2}\right)$ & $27 \pm 6$ & 32.4 & 0.08 \\
Educational status, college (\%) & 28.4 & 53.7 & 0.17 \\
Hypertension (\%) & 45.1 & 26.9 & 0.44 \\
Coronary artery disease (\%) & 14.1 & 31.2 & 0.006 \\
Acute myocardial infarction (\%) & 14.5 & 46.1 & $<0.001$ \\
Dyslipidemia (\%) & 40.6 & 17.5 & 0.001 \\
Diabetes mellitus type 2 (\%) & 14.3 & 13.7 & 0.07 \\
Depression (\%) & 24.7 & 15.8 & 0.16 \\
Anxiety (\%) & 21.6 & 15.4 & $<0.001$ \\
Obstructive pulmonar chronic disease (\%) & 16.9 & 1.1 & 0.02 \\
Asthma (\%) & 1.6 & & 0.50 \\
\hline
\end{tabular}

Multivariate models with the inclusion of variables were: age, race/color, FTND score and drug group.

A stratified analysis by self-reported race showed the following odds ratios for white women $(\mathrm{OR}=1.67 ; 95 \%$ $\mathrm{CI}=1.06$ to $2.43 ; P=0.03$ and $\mathrm{OR}=1.64 ; 95 \% \mathrm{CI}=1.01$ to $2.73 ; P=0.04)$ and for non-white women $(\mathrm{OR}=1.54$; $95 \% \mathrm{CI}=1.03$ to $3.23 ; P=0.04$ and $\mathrm{OR}=2.06 ; 95 \% \mathrm{CI}=$ 0.99 to $4.28 ; P=0.05)$, respectively. Males and females were analyzed together with the genotypes by sex interaction, but the finding was not significant.

Women showed a higher incidence of both depression and anxiety than men $(69.0 \%$ vs. $31.0 \%, P=0.001 ; 63.8 \%$ vs. $36.2 \%, P=0.03$, respectively). Given these differences, the variables depression and/or anxiety were tested in logistic regression. These variables were not associated with treatment success in this model. However, GA and AA genotypes for rs2036527 and rs16969968 polymorphisms remained significantly associated.

\section{FTND score according to CHRNA2, CHRNA3, CHRNA5, CHRNB3 polymorphisms}

We did not observe significant differences in the FTND score according to CHRNA2 rs2472553, CHRNA3 rs1051730, CHRNA5 rs16969968, CHRNA5 rs2036527 and CHRNB3 rs6474413 polymorphisms in the overall patient group $(n=899)$ (Additional file 1: Table S3). In addition, studied polymorphisms were not associated with FTND score in multiple linear regression models (Additional file 1: Table S4).

\section{Discussion}

The main findings of this study was the association of GA and AA genotypes for both CHRNA5 rs16969968 and rs2036527 polymorphisms with increased success rate in smoking cessation treatment in women. Many studies have identified the association of polymorphisms in the CHRNA5- $A 3-B 4$ gene with smoking cessation in response to smoking cessation therapies [2, 29-31]. Recently, our group of researchers found the association of the CHRNA4 rs10443196 and cytochrome P450 2B6 (CYP2B6) 785A $>$ G polymorphisms with a higher success rate in varenicline and bupropion treatment, respectively $[32,33]$.

The association of the CHRNA5 rs16969968 polymorphism with higher rates of success in smoking cessation treatment in women is corroborated by previous studies. As shown in vitro experiments Bierut et al. [14] and Kuryatov et al. [34], individuals carrying the allele A may express $\mathrm{nAChR}$ subtypes composed by $\alpha 5$ subunits with reduced function. Bergen et al. [35] showed that a lower frequency of the allele for rs1051730, which is in strong linkage disequilibrium with rs16969968, was associated with a higher withdrawal rate with NRT. Bergen et al. pointed out that smokers with reduced function of the $\alpha 5$ subunit and associated with increased ND may have greater difficulty quitting. However, they suggested that the prescription of NRT can improve cognitive performance in smoking abstinence, maintaining the normal functioning of the brain after quitting, and this effect may be stronger for individuals with the rs1051730 risk allele. Similarly, Chen et al. [36] reported that individuals with the AA genotype for the rs16969968 had higher withdrawal rate in the treatment with NRT. In the study by Jensen et al. [37], the A allele was associated with lower rates of aversive effects to the nicotine and also with improvement in cognitive control. Jensen et al. suggested that the A allele may be important in tolerability and in response to treatments with NRT. They added that, remarkably, the $\alpha 5$ subunit plays an essential role in mediating aversive effects to the 
Table 2 Success rate in smoking cessation for patients according to genotypes

\begin{tabular}{|c|c|c|c|c|}
\hline \multirow{3}{*}{ Patient groups } & \multicolumn{4}{|c|}{ CHRNA2 rs 2472553} \\
\hline & \multicolumn{3}{|c|}{ Success rate (\%) } & \multirow[b]{2}{*}{$P$ value } \\
\hline & $\overline{C C}$ & $\mathrm{CT}$ & $\pi$ & \\
\hline Overall group $(n=737)$ & 44.7 & 47.5 & 46.2 & 0.81 \\
\hline Women $(n=395)$ & 40.6 & 41.2 & 71.4 & 0.26 \\
\hline Men $(n=342)$ & 49.4 & 54.5 & 16.7 & 0.19 \\
\hline \multicolumn{5}{|l|}{ CHRNA3 rs1051730 } \\
\hline \multirow[t]{2}{*}{ Patient groups } & \multicolumn{4}{|c|}{ Success rate (\%) } \\
\hline & $\mathrm{CC}$ & $\mathrm{CT}$ & $\pi$ & $P$ value \\
\hline Overall group $(n=742)$ & 44.8 & 45.6 & 50.6 & 0.64 \\
\hline Women $(n=396)$ & 36.6 & 43.5 & 51.0 & 0.14 \\
\hline Men $(n=346)$ & 54.3 & 47.9 & 50.0 & 0.52 \\
\hline \multicolumn{5}{|l|}{ CHRNA5 rs 16969968} \\
\hline \multirow[t]{2}{*}{ Patient groups } & \multicolumn{4}{|c|}{ Success rate (\%) } \\
\hline & GG & GA & AA & $P$ value \\
\hline Overall group $(n=731)$ & 43.0 & 46.6 & 54.3 & 0.18 \\
\hline Women $(n=389)$ & 35.7 & 44.0 & 56.3 & 0.03 \\
\hline Men $(n=342)$ & 52.0 & 49.1 & 51.5 & 0.87 \\
\hline \multicolumn{5}{|l|}{ CHRNA5 rs2036527 } \\
\hline \multirow[t]{2}{*}{ Patient groups } & \multicolumn{4}{|c|}{ Success rate (\%) } \\
\hline & GG & GA & AA & $P$ value \\
\hline Overall group $(n=734)$ & 43.9 & 44.4 & 55.0 & 0.13 \\
\hline Women $(n=391)$ & 34.8 & 41.5 & 56.5 & 0.01 \\
\hline Men $(n=343)$ & 53.8 & 47.5 & 52.6 & 0.53 \\
\hline \multicolumn{5}{|l|}{ CHRNB3 rs6474413 } \\
\hline \multirow[t]{2}{*}{ Patient groups } & \multicolumn{4}{|c|}{ Success rate (\%) } \\
\hline & GG & GA & $\mathrm{AA}$ & $P$ value \\
\hline Overall group $(n=727)$ & 46.0 & 46.0 & 45.9 & 1.00 \\
\hline Women $(n=388)$ & 41.7 & 44.4 & 39.5 & 0.64 \\
\hline Men $(n=339)$ & 51.9 & 47.8 & 52.8 & 0.67 \\
\hline
\end{tabular}

nicotine. Interestingly, King et al. [31] showed the association of others risk alleles for ND in locus chr15q25 with lower incidence of nausea. The authors suggest that this may be explained by the tolerance, because individuals with higher ND have higher daily intake of nicotine, are more tolerant and therefore are less likely to experience nausea in response to a nicotinic partial agonist such as varenicline. Therefore, reduced function of the $\alpha 5$ subunit, the higher tolerability of NRT and varenicline and improvement of cognitive control may be possible explanations for the association of rs16969968 with success in this study. One other possibility is that the rs16969968 can be in linkage disequilibrium with other functional polymorphisms that could be involved in smoking cessation process and/or mechanisms in response to the NRT.
Table 3 Multivariate logistic regression analysis for success in smoking cessation according to the CHRNA5 rs16969968 $(n=$ $389)$ and rs2036527 $(n=391)$ polymorphisms in women

\begin{tabular}{llll}
\hline & OR & $95 \%$ Cl & $P$ value \\
\hline Genotypes GA or AA for CHRNA5 rs16969968 & 1.63 & $1.04-2.54$ & 0.03 \\
Age & 0.99 & $0.98-1.01$ & 0.34 \\
Race/color self-declared, White & 1.20 & $0.76-1.91$ & 0.43 \\
FTND score & 0.96 & $0.88-1.05$ & 0.35 \\
Drug group & 1.01 & $0.83-1.25$ & 0.86 \\
& OR & $95 \%$ Cl & P value \\
Genotypes GA or AA for CHRNA5 rs2036527 & 1.59 & $1.02-2.48$ & 0.04 \\
Age & 0.99 & $0.97-1.01$ & 0.33 \\
Race/color self-declared, White & 1.28 & $0.82-2.00$ & 0.29 \\
FTND score & 0.97 & $0.87-1.05$ & 0.44 \\
Drug group & 1.01 & $0.83-1.24$ & 0.93 \\
\hline FTND Fagr
\end{tabular}

FTND Fagerström test for nicotine dependence

There was a higher frequency of depression and/or anxiety in the women's group, which according to some studies could reduce success rates in the smoking cessation treatment [38-42]. Zawertailo et al. [38] conducted a study of 13,000 smokers and found that individuals with recurrent depression were significantly less likely to quit smoking compared to those with no history of depression. Goodwin et al. [39] found that panic attacks and social anxiety disorder were more likely in female smokers than male smokers. Stepankova et al. [40], in a study of 1730 smokers, found that 289 had a history of depression. The tobacco abstinence rate at 1 year was $32.5 \%$ for smokers with a history of depression and $38.7 \%$ for those with no history. In our study, although the frequencies of depression and anxiety were higher in women than in men, these variables were not associated with treatment outcome and rs16969968 and rs2036527 polymorphisms remained significantly associated with smoking cessation in a multivariate model.

There are evidences that gender can be an important factor in smoking cessation process. Beltz et al. [43], evaluating functional magnetic resonance imaging and behavioral data from 50 adult daily smokers (23 women), found that women had an increased nicotine tolerance when compared to men. Smith et al. [44] found that women were $31 \%$ less likely to quit smoking than men. Pierce et al. [45] reported significant sex differences in smoking cessation. They observed the women had weight gain, higher prevalence of depression disorders and increased need of social support to stop smoking.

Some studies showed that several factors may influence sex/gender differences [46], such as biopsychosocial factors, menstrual cycle, hormonal $[47,48]$, having children or not, and smoking cessation medication [44, 49].

In the present study, we found no association of CHRNA2 rs2472553, CHRNA3 rs1051730 and CHRNB3 
rs6474413 polymorphisms with treatment outcome. The results of our study corroborate the findings of previous studies. Ruyck et al. [50] and Sarginson et al. [2] found no association for rs1051730 with outcome of treatment. However, Munafo et al. [51] identified the T allele associated with decreased likelihood of smoking cessation. Bergen et al. [35] associated the $\mathrm{T}$ allele with higher withdrawal rates with NRT and lower withdrawal rate in placebo treatment.

Regarding FTND score, several studies have identified the association of polymorphisms in genes encoding $\mathrm{nAChR}$ alpha and beta subunits with FTND and, number of cigarettes per day [52-57]. However, our study found no significant association of the polymorphisms studied with FTND, consistent with the findings of previous studies, which found no association of CHRNA3 rs1051730, CHRNA5 rs16969968, CHRNA5 rs2036527 or CHRNA5 rs64744413 polymorphisms with phenotypes related to smoking, including ND [58-62].

Etter et al. [62] suggested that the reason for missing association of polymorphisms studied, including rs16969968, can be explained by the difference in the methods used, or due to the small sample size. Amos et al. [61] did not find association of rs16969968 polymorphism with smoking behavior in either African American case patients or African American control participants. The authors point out some limitations of no association with the studied phenotypes, as the sample size limited and also because individuals come from a single center; it is possible that some degree of population structure influenced the findings.

There are some limitations in our study that should be mentioned. First, most patients treated at the PAF were classified as moderately or highly dependent, which may have affected the analysis of association between genotypes and FTND score. Second, the race/color of patients was self-report and we did not performed genetic ancestry. Third, we did not perform the correction of $P$ values for multiple testing. Fourth, besides the available variables used in the multivariate models other relevant factors that could be important, such as the functionality of the receptors, motivation to quit smoking, biopsychosocial and others factors related to sex/gender, could have influenced the results.

\section{Conclusion}

We showed that CHRNA5 rs16969968 and rs2036527 polymorphisms were associated with higher rates of success in smoking cessation treatment in the female group. These results might contribute to advances in personalized medicine.

\section{Additional files}

Additional file 1: Table S1. included: polymorphisms, primer F, primer $\mathrm{R}$ and base pairs. (DOCX $22 \mathrm{~kb}$ )

Additional file 2: Figure S1. Graphs of the CHRNA5 rs16969968 genotyping. Nucleotide changes results in different curve patterns using high resolution melting analysis. A: Graph of normalized fluorescence by temperature. B: Graph of normalized fluorescence (based on genotype 2) by temperature. $1=\mathrm{GG}, 2=\mathrm{GA}, 3=\mathrm{AA}$. (DOCX $114 \mathrm{~kb})$

\section{Abbreviations}

CA: Continuous abstinence; CAPPesq: Comissão de Ética para Análises de Projetos de Pesquisa; CHRNA2: cholinergic receptor nicotinic alpha 2; CHRNA3: cholinergic receptor nicotinic alpha 3; CHRNA5: cholinergic receptor nicotinic alpha 5; CHRNB3: cholinergic receptor nicotinic beta 3; CO: Endexpiratory exhaled carbon monoxide; CYP2B6: cytochrome P450 2B6; DNA: deoxyribonucleic acid; FTND: Fagerström test for nicotine dependence; FTQ: Fagerström tolerance questionnaire; HRM: high resolution melting; HWE: Hardy-Weinberg equilibrium; InCor: Heart Institute; Issa score: Issa situational smoking scores; nAChR: Nicotinic acetylcholine receptor; ND: nicotine dependence; NRT: Nicotine replacement therapy; OR: odds ratio; PAF: Programa de Assistência ao Fumante /Smoker Assistance Program; PCR: polymerase chain reaction

\section{Acknowledgments}

We thank the patients who participated in the study. The technical assistance of the Laboratory of Genetics and Molecular Cardiology group.

\section{Funding}

PCJL Santos is recipient of a fellowship and funding from FAPESP (Proc. 2013-09295-3 and Proc. 2013-20614-3) and from CNPq (Proc. 470410/2013-2), Brazil. PRX Tomaz is recipient of a fellowship from CAPES, Brazil. JR Santos is recipient of a fellowship from CNPq, Proc. 167587/2013-7, Brazil.

\section{Availability of data and materials}

We do not wish to share our data because more clinical variable will be studied.

\section{Authors' contributions}

PRXT, PCJLS and JRS carried out the molecular genetic and statistical analysis, and drafted the manuscript. PCJLS, JSI, TOA, PVG, ABN, JEK and ACP participated in the design of the study. JSI, TOA and PVG selected the patients. PCJLS and ABN assisted in the correction of the manuscript. All authors contributed critically to the manuscript, whose present version was read and approved by all.

\section{Ethics approval and consent to participate}

The study protocol was approved by the Ethics Committee for Medical Research on Human Beings of the Clinical Hospital of the University of São Paulo Medical School (SDC 4024/14/004). Signed informed consent will be obtained from all participants.

\section{Consent for publication}

Not applicable.

\section{Competing interests}

The authors declare that they have no competing interests. JSI is the Principal Site Investigator in Varenicline Trials promoted by Pfizer.

\section{Publisher's Note}

Springer Nature remains neutral with regard to jurisdictional claims in published maps and institutional affiliations.

\section{Author details}

'Laboratory of Genetics and Molecular Cardiology, Instituto do Coracao (InCor), Hospital das Clinicas HCFMUSP, Faculdade de Medicina, Universidade de Sao Paulo, Sao Paulo, SP, Brazil. ' Smoking Cessation Program Department, Instituto do Coracao (InCor), Hospital das Clinicas HCFMUSP, Faculdade de Medicina, Universidade de Sao Paulo, Sao Paulo, SP, Brazil. ${ }^{3}$ Department of 
Pharmacology, Universidade Federal de Sao Paulo - UNIFESP, Sao Paulo, SP, Brazil.

\section{Received: 31 October 2016 Accepted: 23 March 2018} Published online: 05 April 2018

\section{References}

1. Saccone SF, Hinrichs AL, Saccone NL, Chase GA, Konvicka K, Madden PA, Breslau N, Johnson EO, Hatsukami D, Pomerleau O, et al. Cholinergic nicotinic receptor genes implicated in a nicotine dependence association study targeting 348 candidate genes with 3713 SNPs. Hum Mol Genet. 2007;16(1):36-49.

2. Sarginson JE, Killen JD, Lazzeroni LC, Fortmann SP, Ryan HS, Schatzberg AF, Murphy GM Jr. Markers in the 15q24 nicotinic receptor subunit gene cluster (CHRNA5-A3-B4) predict severity of nicotine addiction and response to smoking cessation therapy. Am J Med Genet B Neuropsychiatr Genet. 2011; 156B(3):275-84.

3. Henningfield JE, Slade J. Tobacco-dependence medications: public health and regulatory issues. Food Drug Law J. 1998;53(suppl):75-114.

4. Laviolette SR, van der Kooy D. The neurobiology of nicotine addiction: bridging the gap from molecules to behaviour. Nat Rev Neurosci. 2004;5(1): $55-65$.

5. Fiore MC, Bailey WC, Cohen SJ, et al. Treating tobacco use and dependence: an introduction to the US Public Health Service Clinical Practice Guideline. Clinical Practice Guideline. Respir Care. 2000;45(10):1196-9.

6. Fiore MC, Jaén CR, Baker TB, et al. Treating Tobacco Use and Dependence: 2008 Update. Clinical Practice Guideline. Rockville: U.S. Department of Health and Human Services. Public Health Service;2008.

7. Slemmer JE, Martin BR, Damaj MI. Bupropion is a nicotinic antagonist. J Pharmacol Exp Ther. 2000;295(1):321-7.

8. Sieminska A, Jassem E, Kita-Milczarska K. Nicotine dependence in an isolated population of Kashubians from North Poland: a population survey. BMC Public Health. 2015:15:80

9. Ho MK, Tyndale RF. Overview of the pharmacogenomics of cigarette smoking. Pharmacogenomics J. 2007;7(2):81-98.

10. Hiroi N, Scott D. Constitutional mechanisms of vulnerability and resilience to nicotine dependence. Mol Psychiatry. 2009;14(7):653-67.

11. Dash B, Lukas RJ, Li MD. A signal peptide missense mutation associated with nicotine dependence alters alpha2*-nicotinic acetylcholine receptor function. Neuropharmacology. 2014;79:715-25.

12. Culverhouse RC, Johnson EO, Breslau N, Hatsukami DK, Sadler B, Brooks Al, Hesselbrock VM, Schuckit MA, Tischfield JA, Goate AM, et al. Multiple distinct CHRNB3-CHRNA6 variants are genetic risk factors for nicotine dependence in African Americans and European Americans. Addiction. 2014;109(5):814-22.

13. Wang S, DvdV A, Xu Q, Seneviratne C, Pomerleau OF, Pomerleau CS, Payne TJ, Ma JZ, Li MD. Significant associations of CHRNA2 and CHRNA6 with nicotine dependence in European American and African American populations. Hum Genet. 2014;133(5):575-86.

14. Bierut $L$, Stitzel JA, Wang JC, Hinrichs AL, Grucza RA, Xuei X, Saccone NL, Saccone SF, Bertelsen S, Fox L, et al. Variants in nicotinic receptors and risk for nicotine dependence. Am J Psychiatry. 2008;165(9):1163-71.

15. Caporaso N, Gu F, Chatterjee N, Sheng-Chih J, Yu K, Yeager M, Chen C, Jacobs K, Wheeler W, Landi MT, et al. Genome-wide and candidate gene association study of cigarette smoking behaviors. PLoS One. 2009;4(2):e4653.

16. Stevens VL, Bierut LJ, Talbot JT, Wang JC, Sun J, Hinrichs AL, Thun MJ, Goate A, Calle EE. Nicotinic receptor gene variants influence susceptibility to heavy smoking. Cancer Epidemiol Biomark Prev. 2008;17(12):3517-25.

17. Issa JS, Abe TO, Moura S, Santos PC, Pereira AC. Effectiveness of coadministration of varenicline, bupropion, and serotonin reuptake inhibitors in a smoking cessation program in the real-life setting. Nicotine Tob Res. 2013;15(6):1146-50.

18. Issa JS, Santos PC, Vieira LP, Abe TO, Kuperszmidt CS, Nakasato M, Cardoso E, Amorim C, Pereira AC. Smoking cessation and weight gain in patients with cardiovascular disease or risk factor. Int J Cardiol. 2014;172(2):485-7.

19. Fagerstrom KO, Heatherton TF, Kozlowski LT. Nicotine addiction and its assessment. Ear Nose Throat J. 1990;69(11):763-5.

20. Issa JS. A new nicotine dependence score and a new scale assessing patient comfort during smoking cessation treatment. J Bras Pneumol. 2012; 38(6):761-5
21. Santos PC, Soares RA, Nascimento RM, Machado-Coelho GL, Mill JG, Krieger JE, Pereira AC. SLCO1B1 rs4149056 polymorphism associated with statininduced myopathy is differently distributed according to ethnicity in the Brazilian general population: Amerindians as a high risk ethnic group. BMC Med Genet. 2011;12:136.

22. Santos PC, Soares RA, Santos DB, Nascimento RM, Coelho GL, Nicolau JC, Mill JG, Krieger JE, Pereira AC. CYP2C19 and ABCB1 gene polymorphisms are differently distributed according to ethnicity in the Brazilian general population. BMC Med Genet. 2011;12:13.

23. The Tobacco and Genetics Consortium. Genome-wide meta-analyses identify multiple loci associated with smoking behavior. Nat Genet. 2010;42(5):441-7.

24. Chen LS, Hung RJ, Baker T, Horton A, Culverhouse R, Saccone N, Cheng I, Deng $B$, Han Y, Hansen HM, et al. CHRNA5 risk variant predicts delayed smoking cessation and earlier lung cancer diagnosis-a meta-analysis. J Natl Cancer Inst. 2015;107(5)

25. Bandiera FC, Ross KC, Taghavi S, Delucchi K, Tyndale RF, Benowitz NL. Nicotine dependence, nicotine metabolism, and the extent of compensation in response to reduced nicotine content cigarettes. Nicotine Tob Res. 2015;17(9):1167-72.

26. Hubacek JA, Lanska V, Adamkova V. Lack of an association between SNPS within the cholinergic receptor genes and smoking behavior in a Czech post-MONICA study. Genet Mol Biol. 2014;37(4):625-30.

27. Broms U, Wedenoja J, Largeau MR, Korhonen T, Pitkaniemi J, Keskitalo-Vuokko K, Happola A, Heikkila KH, Heikkila K, Ripatti S, et al. Analysis of detailed phenotype profiles reveals CHRNA5-CHRNA3-CHRNB4 gene cluster association with several nicotine dependence traits. Nicotine Tob Res. 2012;14(6):720-33.

28. Bierut L, Madden PA, Breslau N, Johnson EO, Hatsukami D, OF P, Swan GE, Rutter J, Bertelsen S, Fox L, et al. Novel genes identified in a high-density genome wide association study for nicotine dependence. Hum Mol Genet. 2007;16(1):24-35.

29. Baker TB, Weiss RB, Bolt D, von Niederhausern A, Fiore MC, Dunn DM, Piper ME, Matsunami N, Smith SS, Coon H, et al. Human neuronal acetylcholine receptor A5-A3-B4 haplotypes are associated with multiple nicotine dependence phenotypes. Nicotine Tob Res. 2009;11(7):785-96.

30. Freathy RM, Ring SM, Shields B, Galobardes B, Knight B, Weedon MN, Smith GD, Frayling TM, Hattersley AT. A common genetic variant in the 15q24 nicotinic acetylcholine receptor gene cluster (CHRNA5-CHRNA3-CHRNB4) is associated with a reduced ability of women to quit smoking in pregnancy. Hum Mol Genet. 2009;18(15):2922-7.

31. King DP, Paciga S, Pickering E, Benowitz NL, Bierut LJ, Conti DV, Kaprio J, Lerman C, Park PW. Smoking cessation pharmacogenetics: analysis of varenicline and bupropion in placebo-controlled clinical trials. Neuropsychopharmacology. 2012;37(3):641-50.

32. Rocha Santos J, Tomaz PR, Issa JS, TO A, Krieger JE, Pereira AC, Santos PC. CHRNA4 rs1044396 is associated with smoking cessation in varenicline therapy. Front Genet. 2015;6:46.

33. Tomaz PR, Santos JR, Issa JS, TO A, Gaya PV, Krieger JE, Pereira AC, Santos PC. CYP2B6 rs2279343 polymorphism is associated with smoking cessation success in bupropion therapy. Eur J Clin Pharmacol. 2015;71(9):1067-73.

34. Kuryatov A, Berrettini W, Lindstrom J. Acetylcholine receptor (AChR) alpha5 subunit variant associated with risk for nicotine dependence and lung cancer reduces (alpha4beta2)(2)alpha5 AChR function. Mol Pharmacol. 2011;79(1):119-25.

35. Bergen AW, Javitz HS, Krasnow R, Nishita D, Michel M, Conti DV, Liu J, Lee W, Edlund CK, Hall S, et al. Nicotinic acetylcholine receptor variation and response to smoking cessation therapies. Pharmacogenet Genomics. 2013;23(2):94-103.

36. Chen LS, Baker TB, Jorenby D, Piper M, Saccone N, Johnson E, Breslau N, Hatsukami D, Carney RM, Bierut L. Genetic variation (CHRNA5), medication (combination nicotine replacement therapy vs. varenicline), and smoking cessation. Drug Alcohol Depend. 2015;154:278-82.

37. Jensen KP, DeVito EE, Herman Al, Valentine GW, Gelernter J, Sofuoglu M. A CHRNA5 smoking risk variant decreases the aversive effects of nicotine in humans. Neuropsychopharmacology. 2015;40(12):2813-21.

38. Zawertailo L, Voci S, Selby P. Depression status as a predictor of quit success in a real-world effectiveness study of nicotine replacement therapy. Psychiatry Res. 2015;226(1):120-7.

39. Goodwin RD, Wall MM, Choo T, Galea S, Horowitz J, Nomura Y, Zvolensky MJ, Hasin DS. Changes in the prevalence of mood and anxiety disorders among male and female current smokers in the United States: 1990-2001. Ann Epidemiol. 2014;24(7):493-7.

40. Stepankova L, Kralikova E, Zvolska K, Kmetova A, Blaha M, Bortlicek Z, Sticha $M$, Anders M, Schroeder DR, Croghan IT. Tobacco treatment outcomes in 
patients with and without a history of depression, Czech Republic, 20052010. Prev Chronic Dis. 2013;10:E158.

41. Scott WD, Beevers CG, Mermelstein RJ. Depression vulnerable and nonvulnerable smokers after a failure experience: examining cognitive selfregulation and motivation. Behav Modif. 2008:32(4):519-39.

42. Covey LS, Glassman AH, Stetner F. Depression and depressive symptoms in smoking cessation. Compr Psychiatry. 1990;31(4):350-4.

43. Beltz AM, Berenbaum SA, Wilson SJ. Sex differences in resting state brain function of cigarette smokers and links to nicotine dependence. Exp Clin Psychopharmacol. 2015;23(4):247-54.

44. Smith PH, Kasza KA, Hyland A, Fong GT, Borland R, Brady K, Carpenter MJ, Hartwell K, Cummings KM, McKee SA. Gender differences in medication use and cigarette smoking cessation: results from the international tobacco control four country survey. Nicotine Tob Res. 2015;17(4):463-72.

45. Pierce JP, Lee L, Gilpin EA. Smoking initiation by adolescent girls, 1944 through 1988. An association with targeted advertising. JAMA. 1994;271(8):608-11.

46. Smith PH, Bessette AJ, Weinberger AH, Sheffer CE, McKee SA. Sex/gender differences in smoking cessation: a review. Prev Med. 2016;92:135-40.

47. Weinberger AH, Smith PH, Allen SS, Cosgrove KP, Saladin ME, Gray KM, Mazure $\mathrm{CM}$, Wetherington CL, McKee SA. Systematic and meta-analytic review of research examining the impact of menstrual cycle phase and ovarian hormones on smoking and cessation. Nicotine Tob Res. 2015;17(4):407-21.

48. McVay MA, Copeland AL. Smoking cessation in peri- and postmenopausal women: a review. Exp Clin Psychopharmacol. 2011;19(3):192-202.

49. Perkins KA, Scott J. Sex differences in long-term smoking cessation rates due to nicotine patch. Nicotine Tob Res. 2008;10(7):1245-50.

50. De Ruyck K, Nackaerts K, Beels L, Werbrouck J, De Volder A, Meysman M, Salhi B, Van Meerbeeck J, Thierens H. Genetic variation in three candidate genes and nicotine dependence, withdrawal and smoking cessation in hospitalized patients. Pharmacogenomics. 2010;11(8):1053-63.

51. Munafo MR, Johnstone EC, Walther D, Uhl GR, Murphy MF, Aveyard P. CHRNA3 rs1051730 genotype and short-term smoking cessation. Nicotine Tob Res. 2011;13(10):982-8.

52. Kim DK, Hersh CP, Washko GR, Hokanson JE, Lynch DA, Newell JD, Murphy $J R$, Crapo JD, Silverman EK. Epidemiology, radiology, and genetics of nicotine dependence in COPD. Respir Res. 2011:12:9.

53. Kaur-Knudsen D, Nordestgaard BG, Bojesen SE. CHRNA3 genotype, nicotine dependence, lung function and disease in the general population. Eur Respir J. 2012;40(6):1538-44.

54. Petrovsky N, Ettinger U, Kessler H, Mossner R, Wolfsgruber S, Dahmen N, Maier W, Wagner M, Quednow BB. The effect of nicotine on sensorimotor gating is modulated by a CHRNA3 polymorphism. Psychopharmacology. 2016;229(1):31-40.

55. Wen L, Jiang K, Yuan W, Cui W, Li MD. Contribution of variants in CHRNA5/ A3/B4 gene cluster on chromosome 15 to tobacco smoking: from genetic association to mechanism. Mol Neurobiol. 2016;53(1):472-84.

56. Buczkowski K, Sieminska A, Linkowska K, Czachowski S, Przybylski G, Jassem E, Grzybowski T. Association between genetic variants on chromosome $15 \mathrm{q} 25$ locus and several nicotine dependence traits in polish population: a case-control study. Biomed Res Int. 2015;2015:350348.

57. Wassenaar CA, Dong Q, Wei Q, Amos Cl, Spitz MR, Tyndale RF. Relationship between CYP2A6 and CHRNA5-CHRNA3-CHRNB4 variation and smoking behaviors and lung cancer risk. J Natl Cancer Inst. 2011;103(17):1342-6.

58. Robinson JD, Versace F, Lam CY, Minnix JA, Engelmann JM, Cui Y, KaramHage M, Shete SS, Tomlinson GE, Chen TT, et al. The CHRNA3 rs578776 variant is associated with an intrinsic reward sensitivity deficit in smokers. Front Psychiatry. 2013;4:114.

59. Erlich PM, Hoffman SN, Rukstalis M, Han JJ, Chu X, Linda Kao WH, Gerhard GS, Stewart WF, Boscarino JA. Nicotinic acetylcholine receptor genes on chromosome 15q25.1 are associated with nicotine and opioid dependence severity. Hum Genet. 2010;128(5):491-9.

60. Verde Z, Santiago C, Rodriguez Gonzalez-Moro JM, de Lucas Ramos P, Lopez Martin S, Bandres F, Lucia A, Gomez-Gallego F. 'Smoking genes': a genetic association study. PLoS One. 2011;6(10):e26668.

61. Amos Cl, Gorlov IP, Dong Q, Wu X, Zhang H, Lu EY, Scheet P, Greisinger AJ, Mills GB, Spitz MR. Nicotinic acetylcholine receptor region on chromosome 15q25 and lung cancer risk among African Americans: a case-control study. J Natl Cancer Inst. 2010;102(15):1199-205.

62. Etter JF, Hoda JC, Perroud N, Munafo M, Buresi C, Duret C, Neidhart E, Malafosse A, Bertrand D. Association of genes coding for the alpha-4, alpha5 , beta- 2 and beta- 3 subunits of nicotinic receptors with cigarette smoking and nicotine dependence. Addict Behav. 2009;34(9):772-5.

\section{Submit your next manuscript to BioMed Central and we will help you at every step:}

- We accept pre-submission inquiries

- Our selector tool helps you to find the most relevant journal

- We provide round the clock customer support

- Convenient online submission

- Thorough peer review

- Inclusion in PubMed and all major indexing services

- Maximum visibility for your research

Submit your manuscript at www.biomedcentral.com/submit
Biomed Central 